Bali Medika Jurnal.

Vol 7 No 2, 2020: 29-37

ISSN : 2615-7047

DOI: https://doi.org/10.36376/bmj.v7i2

Disubmit 23 Oktober 2020

Diterima 14 Desember 2020

\title{
PENGARUH INTERVENSI SENAM HAMIL DALAM MENURUNKAN STRES DAN MENINGKATKAN KUALITAS TIDUR IBU HAMIL TRIMESTER III
}

\author{
THE EFFECT OF PREGNANCY EXERCISE \\ INTERVENTION IN REDUCING STRESS AND \\ IMPROVING SLEEP QUALITY ON PREGNANT \\ WOMEN IN THEIR THIRD TRIMESTER
}

\author{
Ni Nyoman Deni Witari', Ni Nyoman Ayuk Widiani ${ }^{2}$ \\ Diploma III Kebidanan Politeknik Kesehatan Kartini Bali, Indonesia ${ }^{1,2}$
}

\begin{abstract}
ABSTRAK
Senam hamil merupakan salah satu olahraga untuk menyiapkan mental dan jasmani ibu hamil dalam menghadapi kehamilnnya. Selama kehamilan ibu hamil sering mengalami ketidaknyamanan seperti sering berkemih, kram tungkai, sulit tidur dan cemas. Tujuan dari penelitian ini untuk mengetahui pengaruh invervensi senam hamil terhadap tingkat stress dan kualitas tidur ibu hamil. Penelitian ini adalah penelitian analitik dengan one group pretest -posttest design. Sampel pada penelitian ini sebanyak 50 orang dimana tehnik sampling yang digunakan dengan purposive sampling berdasarkan kriteria inklusi dan eksklusi. Instrument pengumpulan data primer dengan pengisian kuesioner Depression Anxiety and Stress Scale (DASS) dan The Pittsburgh Sleep Quality Index (PSQI). Uji analisis perbedaan sebelum dan sesudah intervensi dengan uji Wilcoxon dan untuk analisis hubungan dengan uji Spearman. Hasil penelitian ada perbedaan bermakna $(p=0.000)$ tingkat stress dan ada perbedaan kualitas tidur $(\mathrm{p}=0.000)$ sebelum dan sesudah intervensi senam hamil. Tidak ada hubungan $(\mathrm{p}=0.088)$ tingkat stress dengan kualitas tidur.
\end{abstract}

Kata Kunci: Senam Hamil Tingkat Stres, Kualitas Tidur, Ibu Hamil

\section{ABSTRACT}

Pregnancy exercise is one of the sports used for preparing pregnant women mentally and physically in facing their pregnancy. Problems that often arise during pregnancy are poor sleep quality, high maternal stress level, lower back pain, increased urination frequency and leg cramps. The purpose of this study is to determine the effect of pregnancy exercise on stress and sleep quality as well as the correlation between them. This study is an analytical study with one group pretest-posttest design with a sample of 50 people using a purposive sampling technique based on inclusion and exclusion criteria. The data collection was done through a primary data collection by filling in the Depression Anxiety and Stress Scale (DASS) questionnaire and The Pittsburgh Sleep Quality Index (PSQI) questionnaire. The data was then processed using the Wilcoxon test to see differences in stress levels and sleep quality before and after the implementation of pregnancy exercise on pregnant women and the Spearman test to see the correlation between stress level and sleep quality of pregnant women. The results of stress level before and after the implementation of pregnancy exercise $(p=0.000)$ and the quality of sleep before and after pregnancy exercise $(p=0.000)$ were both statistically significant. The results also showed 
Bali Medika Jurnal.

Vol 7 No 2, 2020: 29-37

ISSN : 2615-7047

DOI: https://doi.org/10.36376/bmj.v7i2

that there was no correlation between stress level and sleep quality of pregnant women ( $p$ $=0.088)$.

Keywords: Pregnant Exercise, Stress Level, Sleep Quality, Pregnant Women

\begin{tabular}{ll}
\hline Alamat Korespondensi & : J1. Piranha No. 2, Sesetan, Denpasar Selatan, Pedungan, Kec. \\
& $\begin{array}{l}\text { Denpasar Sel., Kota Denpasar, Bali } 80223 \\
\text { Ednoksaelus@yahoo.co.id }\end{array}$ \\
\hline
\end{tabular}

\section{PENDAHULUAN}

Pada masa kehamilan akan terjadi perubahan fisiologis pada tubuh ibu hamil sebagai bentuk adaptasi maternal yaitu perubahan fisik, fungsi organ, perubahan sistem hormonal, metabolisme dan perubahan psikologis (Manuaba, 2010). Perubahanyang terjadi dapat menyebabkan ketidaknyamanan pada ibu hamil sehingga ibu seringkali merasakan stress dan gangguan tidur.

Kehamilan trimester III merupakan periode penantian dimana ibu hamil sering mengalami stress menjelang persalinan.. Adanya stress pada kehamilan berdampak kurang baik pada ibu ataupun pada janin. Dampak kurang baik tersebut tidak hanya pada saat kehamilan tetapi dapat berpengaruh juga pada proses kelahiran, pasca kelahiran dan pada masa laktasi. Dari hasil beberapa penelitian dampak buruk yang dapat terjadi akibat ansietas pada kehamilan antara lain: kematian janin intrauterine, abortus, gangguan perkembangan otak janin, kelahiran premature, berat badan lahir rendah (Robin, 2015).

Ketidaknyaman pada kehamilan di trimester III sering menimbulkan gangguan tidur yang disebabkan oleh faktor stres, sering berkemih, nyeri dangerakan pada janin. Gangguan tidur yang sering dialami oleh ibu hamil adalah penurunan durasi tidur yang berdampak pada menurunnya konsentrasi ibu, mudah lelah, pegal, tidak mood bekerja, dan cenderung emosional. Hal ini dapat membuat beban kehamilan menjadi semakin berat dan dapat berpengaruh ke janin (Lamadhah, 2011).

Olahraga ringan selama hamil sangat dianjurkan agar ibu dan janin lebih sehat dan berkurangnya masalah-masalah yang timbul pada kehamilannnya. Salah satu olahraga ringan yang dapat dilakukan ibu hamil ialah senam hamil. Senam hamil merupakan suatu gerakan tubuh berbentuk latihan dengan aturan, sistematika, dan prinsip-prinsip gerakan khusus yang disesuaikan dengan kondisi ibu hamil, bertujuan agar ibu hamil siap mental dan jasmani dalam menghadapi proses persalinan. Gerakan senam hamil terkandung efek relaksasi yang bermanfaat menstabilkan stress, mengurangi rasa takut dan meningkatkan kualitas tidur. (Larasati \& Wibowo, 2012).

Berdasarkan penelitian Larasati \& Kumolohadi (2008) dengan judul penelitian Kecemasan Menghadapi Masa Persalinan Ditinjau dari Keikutsertaaan Ibu dalam Senam Hamil didapatkan hasil bahwa terdapat perbedaan tingkat kecemasan menghadapi persalinan antara kelompok kontrol dan kelompok eksperimen setelah diberikan senam hamil . Sedangkan penelitian mengenai pengaruh senam hamil terhadap peningkatan kualitas tidur pada ibu hamil trimester III telah dilakukan di Kota Semarang pada tahun 2015 pada 17 responden yang menunjukkan adanya perbedaan kualitas tidur sebelum dan sesudah diberikan 
intervensi senam hamil (Yuniasari, 2015). Penelitian oleh Gede Robin pada tahun 2015 menunjukkan adanya hubungan antara tingkat kecemasan dengan kualitas tidur ibu hamil primigravida trimester III.

Kecamatan Sukawati memiliki dua Puskesmas yaitu Puskesmas I Sukawati dan Puskesmas II Sukawati. Salah satu program unggulan Puskesmas ini adalah kelas ibu hamil termasuk senam hamil yang bertujuan untuk meningkatkan derajat kesehatan teruatama Kesehatan Ibu dan Anak (KIA). Program tersebut secara rutin dilakukan oleh pihak Puskesmas setiap satu minggu sekali. Berdasarkan latar belakang di atas mengingat dampak yang ditimbulkan oleh stress pada kehamilan dan kualitas tidur ibu hamil yang berpengaruh terhadapp ibu dan janin serta besarnya manfaat senam hamil untuk mengatasi ketidaknyamanan ibu hamil maka peneliti tertarik untuk melakukan penelitian tentang pengaruh senam hamil terhadap tingkat stres dan kualitas tidur pada ibu hamil di Kecamatan Sukawati.

Tujuan umum dari penelitian ini adalah untuk mengetahui pengaruh intervensi senam hamil terhadap penurunan tingkat stress dan peningkatan kualitas tidur. Tujuan Khusus untuk mengetahui tingkat stress sebelum dan sesudah diberikan intervensi senam hamil, untuk mengetahui kualitas tidur sebelum dan sesudah diberikan intervensi senam hamil, untuk mengetahui hubungan stress dengan kualitas tidur.

\section{METODE PENELITIAN}

Penelitian ini merupakan penelitian analitik dengan rancangan one group pretest-posttest without control yaitu observasi dilakukan sebanyak dua kali, sebelum perlakuan dan setelah perlakuan pada satu kelompok tanpa kelompok pembanding/control. Penelitian ini dilaksanakan di kecamatan Sukawati dengan jumlah sampel $50 \mathrm{ibu}$ hamil. Tehnik sampling yang digunakan adalah purposive sampling dimana sampel yang digunakan memenuhi kriteria inklusi yaitu ibu hamil TM III tanpa komplikasi, ibu primi dan multipara, dan ibu yang belum pernah melakukan senam hamil. Cara pengumpulan data dengan mengurus ijin penelitian ke instansi terkait. Data yang dikumpulkan yaitu data sekunder dari buku KIA untuk mengetahui riwayat kehamilan dan data primer langsung wawancara dengan responden. Instrumen yang digunakan yaitu kuesioner Depression Anxiety and Stress Scale (DASS) untuk mengukur tingkat stress dan kuesioner The Pittsburgh Sleep Quality Index (PSQI) untuk mengukur kualitas tidur. Prosedur penelitian subyek yang memenuhi kriteria inklusi diberikan informed consent untuk kesediaannya memberikan informasi yang dibutuhkan dan bersedia melakukan senam hamil. Subyek penelitian yang sudah bersedia akan dikaji data dengan memberikan kuesioner tentang stress, kualitas tidur dan materi tentang senam hamil. Pengkajian ini dilakukan sebanyak $2 x$ sebelum dan sesudah diberikan senam hamil dan minimal sudah melakukan senam hamil minimal sebanyak 4x. Tehnik analisi data dengan analisis univariat, analisis bivariat dengan uji wicolxon 


\section{HASIL}

\section{HASIL DAN PEMBAHASAN}

Tabel 1. Distribusi Frekuensi Stres Ibu Hamil Trimester III Sebelum Diberikan Intervensi Senam Hamil di Kecamatan Sukawati Tahun 2020

\begin{tabular}{cccc}
\hline No & Stres & Frekuensi (f) & Persentase (\%) \\
\hline 1 & Berat & 4 & 8.0 \\
2 & Normal & 31 & 62.0 \\
3 & Sedang & 6 & 12.0 \\
4 & Ringan & 9 & 18 \\
\hline & Total & $\mathbf{5 0}$ & $\mathbf{1 0 0}$ \\
\hline
\end{tabular}

Sumber Data Primer 2020

Berdasarkan tabel 1 menunjukkan bahwa dari 50 responden sebelum intervensi senam hamil yaitu sebagian kecil 4 responden (8,5\%) tingkat stres berat dan Sebagian besar 31 orang $(62 \%)$ berada di tingkat stres normal

Tabel 2. Distribusi Frekuensi Stres Ibu Hamil Trimester III Sesudah Diberikan Intervensi Senam Hamil di Kecamatan Sukawati Tahun 2020

\begin{tabular}{cccc}
\hline No & Kecemasan & Frekuensi (f) & $\begin{array}{c}\text { Persentase } \\
(\mathbf{\%})\end{array}$ \\
\hline 1 & Normal & 44 & 88.0 \\
2 & Ringan & 6 & 12.0 \\
\hline Total & & $\mathbf{5 0}$ & $\mathbf{1 0 0}$ \\
\hline
\end{tabular}

Sumber Data Primer 2020

Berdasarkan tabel 2 menunjukkan bahwa dari 50 responden sesudah intervensi senam hamil yaitu sebagian kecil 6 responden (12\%) tingkat stres ringan dan Sebagian besar 44 orang $(88 \%$ ) berada di tingkat stres normal

Tabel 3. Distribusi Frekuensi Kualitas Tidur Ibu Hamil Trimester III Sebelum Diberikan Intervensi Senam Hamil di Kecamatan Sukawati Tahun 2020

\begin{tabular}{cccc}
\hline No & Kualitas Tidur & Frekuensi (f) & $\begin{array}{c}\text { Persentase } \\
(\boldsymbol{\%})\end{array}$ \\
\hline 1 & Baik & 9 & 18.0 \\
2 & Buruk & 41 & 82.0 \\
\hline Total & & $\mathbf{5 0}$ & $\mathbf{1 0 0}$ \\
\hline \multicolumn{2}{l}{ Sumber Data Primer 2020 } & &
\end{tabular}

Berdasarkan tabel 3 menunjukkan bahwa dari 50 responden sebelum intervensi senam hamil yaitu sebagian kecil 9 responden (18\%) kualitas tidurnya baik dan Sebagian besar 41 orang ( $82 \%$ ) kualitas tidurnya buruk 
DOI: https://doi.org/10.36376/bmj.v7i2

Tabel 4. Distribusi Frekuensi Kualitas Tidur Ibu Hamil Trimester III Sesudah Diberikan Intervensi Senam Hamil di Kecamatan Sukawati Tahun 2020

\begin{tabular}{cccc}
\hline No & Kualitas Tidur & Frekuensi (f) & $\begin{array}{c}\text { Persentase } \\
(\mathbf{\%})\end{array}$ \\
\hline 1 & Baik & 39 & 78.0 \\
2 & Buruk & 11 & 22.0 \\
\hline Total & & $\mathbf{5 0}$ & $\mathbf{1 0 0}$ \\
\hline
\end{tabular}

Sumber Data Primer 2020

Berdasarkan tabel 4 menunjukkan bahwa dari 50 responden sebelum intervensi senam hamil yaitu sebagian kecil 11 responden (1\%) kualitas tidurnya buruk dan Sebagian besar 39 orang (78\%) kualitas tidurnya baik

Berdasarkan uji normalitas pada sebaran data stres, didapatkan nilai signifikansi untuk stress pretest sebesar 0,014 dan stress post 0,01 lebih rendah dari 0.05 maka data dianggap tidak berdistribusi normal. maka untuk menguji perbedaan nilai tingkat kecemasan digunakan uji Wilcoxon

Tabel 5. Pengaruh Stres Ibu Hamil Trimester III Sebelum Dan Sesudah Diberikan Intervensi Senam Hamil di Kecamatan Sukawati Tahun 2020 Wilcoxon Signed Ranks Test

\begin{tabular}{|ll|r|r|r|}
\hline \multicolumn{1}{|c|}{ Ranks } & N & Mean Rank & \multicolumn{1}{c|}{$\begin{array}{c}\text { Sum of } \\
\text { Ranks }\end{array}$} \\
\hline stres_post - stres_pre & Negative Ranks & $38^{\mathrm{a}}$ & 21.63 & 822.00 \\
& Positive Ranks & $3^{\mathrm{b}}$ & 13.00 & 39.00 \\
& Ties & $9^{\mathrm{c}}$ & & \\
\cline { 2 - 5 } & Total & 50 & & \\
\hline
\end{tabular}

a. stres_post < stres_pre

b. stres_post $>$ stres_pre

c. stres_post $=$ stres_pre

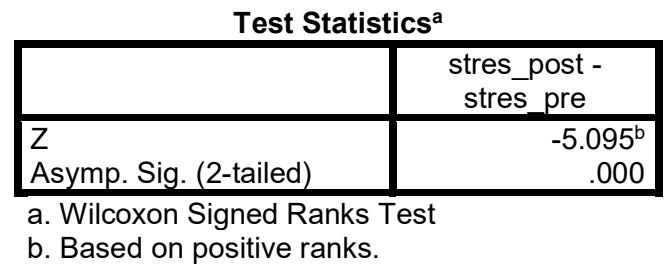

Berdasarkan tabel 5. hasil uji diperoleh nilai $Z$ hitung sebesar $-5,095$ dengan nilai $\mathrm{p}=0,000<0,05$. Artinya terdapat perbedaan yang signifikan stres ibu hamil sebelum dan sesudah intervensi senam hamil.

Berdasarkan uji normalitas pada sebaran data kualitas tidur, didapatkan nilai signifikansi untuk kualitas tidur pretest sebesar 0,01 dan stress post 0,00 lebih rendah dari 0.05 maka data dianggap tidak berdistribusi normal. maka untuk menguji perbedaan nilai tingkat kualitas tidur digunakan uji Wilcoxon 
Tabel 7. Pengaruh Kualitas Tidur Ibu Hamil Trimester III Sebelum Dan Sesudah Diberikan Intervensi Senam Hamil di Kecamatan Sukawati Tahun 2020

\section{Wilcoxon Signed Ranks Test}

\begin{tabular}{|ll|r|r|r|}
\multicolumn{2}{c|}{ Ranks } & $\mathrm{N}$ & Mean Rank & Sum of Ranks \\
\hline Kualitas_tidur_post & - Negative Ranks & $45^{\mathrm{a}}$ & 23.00 & 1035.00 \\
Kualitas_tidur_pre & Positive Ranks & $0^{\mathrm{b}}$ & .00 & .00 \\
& Ties & $5^{\mathrm{c}}$ & & \\
\cline { 2 - 5 } & Total & 50 & & \\
\hline
\end{tabular}

a. Kualitas_tidur_post $<$ Kualitas_tidur_pre

b. Kualitas_tidur_post $>$ Kualitas_tidur_pre

c. Kualitas_tidur_post $=$ Kualitas_tidur_pre

\begin{tabular}{|l|r|}
\hline \multicolumn{2}{|c|}{$\overline{\text { Test Statistics }}^{\mathbf{a}^{\mathrm{-}}}$} \\
& $\begin{array}{r}\text { Kualitas_tidur_po } \\
\text { st - } \\
\text { Kualitas_tidur_pre }\end{array}$ \\
\hline Z & $-5.881^{\mathrm{b}}$ \\
Asymp. Sig. (2-tailed) & .000 \\
\hline
\end{tabular}

a. Wilcoxon Signed Ranks Test

b. Based on positive ranks.

Berdasarkan tabel 7 hasil uji diperoleh nilai $\mathrm{Z}$ hitung sebesar -5,881 dengan nilai $p=0,000<0,05$. Artinya terdapat perbedaan yang signifikan kualitas tidur ibu hamil sebelum dan sesudah intervensi senam hamil.

Tabel 8. Hubungan Stress dengan Kualitas Tidur Ibu Hamil TM III Setelah Intervensi Senam Hamil Di Kecamatan Sukawati Tahun 2020

\section{Correlations}

\begin{tabular}{|ll|r|r|}
\hline \multicolumn{1}{c}{ Correlations } & Kualitas_tidur_pos \\
& & Kecemasan_post & t \\
\hline stress_post & Pearson Correlation & 1 & -.244 \\
& Sig. (2-tailed) & 50 & .088 \\
& $\mathrm{~N}$ & -.244 & 50 \\
\hline Kualitas_tidur_post & Pearson Correlation & .088 & 1 \\
& Sig. (2-tailed) & 50 & 50 \\
& $\mathrm{~N}$ & & 5 \\
\end{tabular}

\section{PEMBAHASAN}

1. Pengaruh Intervensi Senam Hamil Terhadap Penurunan Tingkat Stress Ibu Hamil di Trimester III

Pada hasil penelitian ini ditemukan ada perbedaan antara tingkat stress ibu hamil sebelum dan sesudah diberikan intervensi senam hamil dimana nilai $\mathrm{p}=0.000$ kurang dari 0.05 melalui uji Wicoxon. Hal ini sejalan dengan penelitian yang dilakukan oleh Murbiah (2014) dimana ada pengaruh pemberian senam hamil terhadap tingkat kecemasan yang dilakukan di Palembang. Berdasarkanpenelitian 
Larasati \& Kumolohadi (2008) dengan judul penelitian Kecemasan Menghadapi Masa Persalinan Ditinjau dari Keikutsertaaan Ibu dalam Senam Hamil didapatkan hasil bahwa terdapat perbedaan tingkat kecemasan menghadapi persalinan antara kelompok kontrol dan kelompok eksperimen setelah diberikan senam hamil

Pada ibu hamil akan mengalami perubahan fisik dan psikologis sehingga membutuhkan tubuh yang sehat dan bugar untuk menjalani masa kehamilan. Senam hamil merupakan olah fisik yang berisi gerakan kebugaran, relaksasi dan pengaturan pernapasan. Dengan melakukan relaksasi dan pengaturan pernapasan secara rutin tubuh menjadi nyaman, tenang, dan menurunkan stress dan rasa cemas menjelang persalinan (Maryunani \& Sukaryati, 2011). Manfaat senam hamil sangat diperlukan oleh ibu hamil dimana setiap gerakan pada senam hamil dapat melatih otot-otot menjadi rileks sehingga dapat berfungsi secara optimal dalam persalinan normal. Saat ini senam hamil merupakan bagian dari program perawatan antenatal di pelayanan kesehatan seperti di rumah sakit, puskesmas dan klinik untuk meningkatkan derajat kesehatan ibu hamil.

2. Pengaruh Intervensi Senam Hamil Terhadap Kualitas Tidur Ibu Hamil di Trimester III

Berdasarkan hasil uji Wicolxon terdapat perbedaan antara sebelum dan sesudah diberikan intervensi senam hamil terhadap kualitas tidur ibu hamil hal ini menunjuk pada $p$ value dimana nilai signifikan $p=0.000$ kurang dari 0.05 .

Hasil penelitian ini sejalan dengan penelitian yang dilakukan oleh Wahyuni \& Ni'mah (2013) dimana senam hamil berpengaruh dalam peningkatan durasi tidur ibu hamil trimester III. Penelitian lainnya tentang pengaruh senam hamil terhadap peningkatan kualitas tidur pada ibu hamil trimester III telah dilakukan di Kota Semarang pada tahun 2015 pada 17 responden yang menunjukkan adanya perbedaan kualitas tidur sebelum dan sesudah diberikan intervensi senam hamil (Yuniasari, 2015).

Seiring dengan bertambahnya usia kehamilan sering kali ibu hamil mengalami kesulitan dan gangguan tidur akibat dari perubahan tubuh seperti, stress, pergerakan janin, uterus semakin membesar, sering buang air kecil, nyeri pinggang, sesak dll. Kualitas tidur yang buruk dapat menimbulkan stress dan rasa cemas yang nantinya akan berpengaruh terhadap kesehatan ibu dan kepada janin yang dikandung ibu (Janiwaty \& Pieter, 2013). Salah satu upaya yang dapat dilakukan ibu didalam meningkatkan kualitas tidur adalah melakukan aktifitas fisik berupa olahraga. Aktifitas fisik yang dimaksud adalah senam hamil yang aman bagi ibu hamil (Kim dkk., 2015). Senam Hamil merupakan salah satu aktifitas fisik yang dianjurkan untuk ibu hamil dengan gerakan yang disesuaikan dengan perubahan tubuh ibu hamil. Manfaat senam hamil dapat membantu ibu menjadi lebih nyaman sehingga ketika ibu hamil merasa rileks maka akan memudahkan untuk tertidur dan mendapatkan tidur nyenyak. Dimana pada saat kualitas tidur ibu baik peran hormone epinephrine menurun (Tortora \& Derrickson, 2009).

\section{Hubungan Tingkat Stress Dengan Kualitas Tidur Ibu hamil Trimester III}

Berdasarkan hasil pengujian hubungan menunjukkan bahwa nilai $\mathrm{p}=0.088$ lebih besar dari 0.05 sehingga dapat disimpulkan bahwa pada penelitian ini tingkat stress tidak memiliki hubungan yang bermakna dengan kualitas tidur. 
Kehamilan trimester tiga disebut juga sebagai periode penantian ibu dan keluarga untuk mempersiapkan kelahiran. Pada periode ini ibu hamil sering kali merasakan kecemasan menjelang persalinan yang berdampak pada kualitas tidur ibu hamil. Beberapa faktor yang menyebabkan ibu hamil sering mengalami gangguan tidur adalah seringnya berkemih pada malam hari, posisi tidur yang kurang nyaman, pembesaran uterus, sesak, nyeri dan gerakan janin. Ketidaknyamanan yang dirasakan ibu apabila tidak ditangani secara serius akan mempengaruhi kesehatan ibu, pertumbuhan dan perkembangan janinnya (Agustin, 2012). Berdasarkan penelitian oleh Robin (2015) menunjukkan adanya hubungan antara tingkat kecemasan dengan kualitas tidur ibu hamil primigravida trimester III

Pada penelitian ini tidak ada hubungan antara stress dengan kualitas tidur hal ini sejalan dengan penelitian yang dilakukan oleh Aliyah, (2016) bahwa kecemasan ibu hamil tidak ada hubungannya dengan kualitas tidur. Dimana pada penelitian ini kualitas tidur dipengaruhi oleh faktor stress namun oleh faktor lain seperti frekuensi berkemih meningkat pada malam hari, sesak dan nyeri

\section{SIMPULAN}

\section{SIMPULAN DAN SARAN}

Berdasarkan hasil penelitian dapat disimpulkan bahwa terdapat pengaruh intervensi senam hamil dalam menurunkan stress ibu hamil dan terdapat pengaruh intervensi senam hamil dalam meningkatkan kualitas tidur ibu hamil dan tidak terdapat hubungan bermakna tingkat kecemasan dengan kualitas tidur pada ibu hamil trimester III.

Keterbatasan penelitian ini dilakukan pada masa pandemi sehingga perencanaan awal dilakukan di puskesmas menjadi kunjungan kerumah sehingga jumlah sampel yang diperoleh 50 responden dengan design one group pretest posttest untuk penelitian selanjutnya agar sampelnya lebih banyak lagi dan dengan design penelitian lainnya serta penambahan variabel lainnya

\section{SARAN}

Berdasarkan penelitian ini dapat disarankan kepada ibu hamil untuk mendapatkan informasi kesehatan kehamilannya di pelayanan kesehatan agar dapat menjalani kehamilannya dengan baik dan dapat memperhatikan kondisinya secara fisik dan psikologis sehingga ibu tidak mudah stress dan dapat menjaga kualitas tidurnya. Ibu hamil dapat melakukan senam hamil di rumah dengan teratur pada masa pandemi ini. Untuk pelayanan kesehatan senam hamil yang merupakan salah satu pelayanan antenatal menjadi pelayanan wajib dan perlu dimantapkan kembali di pelayanan kesehatan lainnya seperti di klinik, pusat kesehatan ibu dan anak. Dengan kondisi pandemi ini agar senam hamil dapat dilakukan secara online.

\section{UCAPAN TERIMA KASIH}

Ucapan terima kasih penulis ucapkan kepada Ibu Ketua Yayasan Kartini Bali, Ibu Direktur Politeknik Kesehatan Kartini Bali serta semua pihak yang telah membantu dalam pelaksanaan penelitian ini. 


\section{DAFTAR PUSTAKA}

Agustin, D. (2012). Faktor-faktor yang Mempengaruhi Kualitas Tidur Pada Pekerja Shift di PT. Krakatau Tirta Industri Cilegon. Skripsi. Universitas Indonesia.

Aliyah, J. (2016). Pengaruh Pemberian Senam Hamil Terhadap Tingkat Kecemasan dan Kualitas Tidur Ibu Hamil di Puskesmas Samata Kabupaten Gowa. Skripsi. Kedokteran Universitas Hasanuddin.

Janiwaty, B., \& Pieter, H. Z. (2013). Pendidikan Psikologi Untuk Bidan. Yogyakarta: ANDI.

Kim, S., Lee, J., Lim, Y., Bang, J., Lee, M., \& Lee, J. (2015). Effects of physical exercise on sleep, quality of life and mood in community-dwelling adults. Sleep Medicine, 16(1), S242.

Lamadhah. (2011). Buku Pintar Kehamilan dan persalinan. Yogyakarta: Diva Press.

Larasati, I. P., \& Wibowo, A. (2012). Pengaruh keikutsertaan senam hamil terhadap kecemasan primigravida trimester ketiga dalam menghadapi persalinan. Jurnal Biometrika dan kependudukan, 1(1), 26-32.

Larasati, M., \& Kumolohadi, R. (2008). Kecemasan menghadapi masa persalinan ditinjau dari keikutsertaan ibu dalam senam hamil. Naskah Publikasi Universitas Islam Indonesia.

Manuaba, I. B. G. (2010). Ilmu kebidanan, penyakit kandungan \& keluarga berencana untuk pendidikan bidan. Jakarta: EGC.

Maryunani, A., \& Sukaryati, Y. (2011). Senam Hamil, Senam Nifas dan Terapi Musik. Jakarta: Trans Info media.

Murbiah. (2014). Pengaruh Senam Hmail Terhadap Tingkat Kecemasan Pada Primigravida Trimester III di Kota Palembang. Skripsi. Universitas Gadjah Mada.

Robin, G. (2015). Hubungan Tingkat Kecemasan dengan Kualitas Tidur pada Ibu Hamil Primigravida Trimester III Di Puskesmas Didorejo Lampung 79 Timur Tahun 2015. Skripsi. Universitas Malahati.

Tortora, G. J., \& Derrickson, B. (2009). Principles of Anatomy and Physiology (12 ed.). USA: Wiley \& Sons.

Wahyuni, \& Ni'mah, L. (2013). Manfaat Senam Hamil Untuk Meningkatkan Durasi Tidur Ibu Hamil. KEMAS: Jurnal Kesehatan Masyarakat, 8(2).

Yuniasari, D. (2015). Pengaruh Senam Hamil Terhadap Peningkatan Kualitas Tidur pad Ibu Hamil Trimester III di Klinik Bidan Hj.Uut S Rahayu. Skripsi. Universitas Islam Sultan Agung. 